\title{
TREATMENT OF SYPHILIS WITH PENICILLIN REVIEW OF 123 CASES TREATED IN H.M. FORCES \\ BY
}

\author{
ROBERT LEES and LESLIE WATT
}

\section{Manchester and Oldham}

The results of treatment of early syphilis with penicillin only have been reported by many observers. Pillsbury (1945) followed 792 patients for 6 or more months after treatment, and found that the number of infectious relapses which occurred was small, and that they usually occurred within 20 weeks. Leifer (1945), using a total dosage of $1 \cdot 2$ mega units of penicillin given in sixty 3-hourly injections, noted that eight patients relapsed out of a total of 96 ; and that six of these relapses occurred during the 4th month, one at 6 months, and one at 13 months after treatment. Downing (1950) has recently drawn attention to one case of early syphilis, treated in the army with 2.4 mega units of penicillin, which apparently relapsed after one year, 2 years, and 4 years.

Downing mentions that his case "represents one of a very large number treated in a similar way during their army service ", and the present article is intended to draw attention to the large number of persons, now members of the civilian population, who contracted early syphilis between 1945 and 1947, and were treated in the forces with penicillin only. The scheme then in general use consisted of 2.4 mega units of penicillin given over $7 \frac{1}{2}$ days, but variations occurred both in total dosage and in the time during which that dosage was administered.

Proof of the efficiency of any particular scheme of treatment of early syphilis must perforce depend on a sufficient number of patients observed over a sufficient period of time (at least 2 years), and it seems very desirable to secure an assessment of the treatment which was so widely used in the services. It is suggested that all venereal-disease clinics in Great Britain might pool their findings in such cases. It seems probable that, because of release from the forces and difficulties in attending recognized centres, the post-treatment observation of these men has often been inadequate and that a proportion may now suffer from latent syphilis or may have a contagious relapse.

\section{Material}

We have obtained the records of 123 men who had suffered from early syphilis in the services and were treated with penicillin. The period of observation

TABLE

PERIOD OF OBSERVATION OF 123 CASES OF SYPHILIS

\begin{tabular}{|c|c|c|c|c|c|c|c|c|c|c|c|}
\hline \multirow{2}{*}{\multicolumn{3}{|c|}{ Stage of Disease }} & \multirow{2}{*}{$\begin{array}{c}\text { No. of } \\
\text { Cases }\end{array}$} & \multicolumn{8}{|c|}{ Months of Observation } \\
\hline & & & & $0-6$ & $7-12$ & $13-18$ & $18-24$ & $25-30$ & $31-36$ & $37-42$ & 43 plus \\
\hline Primary Sero-negative & . & . & 65 & 1 & 3 & 6 & 8 & 27 & 16 & 4 & - \\
\hline Primary Sero-positive & . & . & 49 & 2 & 2 & 6 & 4 & 17 & 14 & 3 & 1 \\
\hline Secondary & . & . & 5 & - & 1 & 一 & - & 3 & 1 & - & - \\
\hline \multicolumn{2}{|l|}{ Early Syphilis Unspecified . } & $\ldots$ & 4 & - & - & - & 1 & 3 & - & - & - \\
\hline \multirow{2}{*}{ Total } & \multirow{2}{*}{. } & \multirow{2}{*}{. } & \multirow{2}{*}{123} & 3 & 6 & 12 & 13 & 50 & 31 & 7 & 1 \\
\hline & & & & \multicolumn{4}{|c|}{34} & \multicolumn{4}{|c|}{89} \\
\hline
\end{tabular}


is shown in the Table, and here it is seen that 89 cases have already been observed for 24 months or longer. Interest centres in seven patients who have shown evidence of possible syphilitic relapse or re-infection, and the histories of these patients are given briefly.

\section{Cases of Relapse or Re-infection}

Case $1(46 / 391)$.

1.5.45 Primary sero-positive syphilis treated in the army with $2 \cdot 4$ mega units penicillin.

Nov., 1945 Blood Wassermann reaction negative, Kahn test negative. Cerebrospinal fluid normal.

28.1.46 Exposed to venereal infection, but no details of consort available.

11.2.46 Noted sore on penis.

18.2.46 Examined at clinic. Serum from ulcer$T$. pallidum present. Wassermann reaction negative.

Re-treated penicillin, neoarsphenamine, and bismuth, but defaulted 29.5.46.

This case might represent either clinical relapse or re-infection. No evidence regarding exact site of original sore forthcoming.

Case 2 (46/5415).

July, 1946 Primary sero-positive syphilis; treated with $4 \cdot 8$ mega units penicillin.

$\left.\begin{array}{r}9.10 .46 \\ 11.12 .46\end{array}\right\}$ Wassermann reaction negative.

1.1.47 Cerebrospinal fluid normal.

7.1.47 Small sore on penis noted. Admitted exposure to infection two months earlier, but no details of consort available.

$8.1 .47)$

10.1.47 No T. pallidum found in serum from sore.

13.1.47

10.1.47 Wassermann reaction doubtful, Kahn test slightly positive.

22.1.47 Dark-field examination-T. pallidum present. Re-treated with penicillin 3.0 mega units, neoarsphenamine $5.85 \mathrm{~g}$., and bismuth $2.0 \mathrm{~g}$.

30.4.47 Wassermann reaction doubtful.

2.6.47 Wassermann reaction negative.

3.10.47 Cerebrospinal fluid normal.

11.5.49 Cerebrospinal fluid normal.

Under observation until 3.6 .49 , remained clinically and serologically negative.

This patient may have exhibited either a clinical and serological relapse or may have been re-infected.

Case 3 (46/5679).

Nov., 1945 Sero-positive primary syphilis treated with $2 \cdot 4$ mega units penicillin. $\left.\begin{array}{l}\text { Jan., } 1946 \\ \text { Mar., 1946 }\end{array}\right\}$ Wassermann reaction negative.

Fresh sexual exposure during latter part of March, 1946. Details of consort unknown.

29.4.46 Presented with penile ulcer and papular lesions on buttocks. Blood Wassermann reaction positive, serum from ulcer contained T. pallidum.

Re-treated with penicillin 4.8 mega units and $0.6 \mathrm{~g}$. mapharside in 10 days. Clinical observation, serological tests and cerebrospinal fluid all normal until 16.4.48 (i.e. 2 years) after which no further tests have been done.

This suggests a relapse, but re-infection is a possibility.

Case 4 (46/1746).

5.3.46 Primary sero-positive syphilis treated with $2 \cdot 4$ mega units penicillin.

23.7.46 Papular eruption on penis and scrotum, enlarged inguinal glands, ulceration of right tonsil and palpable lymph glands in cervical and epitrochlear region. Denied re-exposure. Serum from papules- $T$. pallidum present. Wassermann reaction positive. Re-treated with penicillin 3.75 mega units, bismuth $2.0 \mathrm{~g}$., and neoarsphenamine $5.85 \mathrm{~g}$.

21.10.46 Wassermann reactions and Kahn tests negto ative when tested at two-monthly intervals.

2.10.48 Cerebrospinal fluid twice found to be normal during that period.

This clinical relapse within four months of treatment was subsequently given penicillin in conjunction with neoarsphenamine and bismuth, and no relapse occurred in two years.

Case 5 (47/6341).

1945 Sero-positive primary syphilis treated in N. Africa with 4.0 mega units penicillin. Thereafter six serum tests at monthly intervals. On leaving the service did not attend for further tests.

His wife (Case 47/657) attended an ante-natal clinic and her blood gave a positive Wassermann reaction, so he was asked to attend for examination.

16.10.47 There was no clinical evidence of neurosyphilis. The superficial lymph glands were enlarged, but there was no suggestive lesion of the skin or mucous membrane, or other sign of syphilis. Blood Wassermann reaction positive, Kahn test positive. Cerebrospinal fluid : cells 128 per c.mm.; protein, $70 \mathrm{mg}$./ $100 \mathrm{ml}$; Wassermann reaction positive; Lange 012210000 .

Re-treated with 5.0 mega units penicillin and daily injections of mapharside $0.06 \mathrm{~g}$. for 5 days, followed by $0.06 \mathrm{~g}$. mapharside bi-weekly, and bismuth $0.2 \mathrm{~g}$. weekly for ten weeks. 
2.3.48 Blood Wassermann reaction positive. Cerebrospinal fluid : cells 2 ; protein, $27 \mathrm{mg}$. $/ 100$ ml.; Wassermann reaction negative; Lange 0000000000.

30.4.48 Blood Wassermann reaction positive. Given a further course of neoarsphenamine $5.85 \mathrm{~g}$. and bismuth $2.0 \mathrm{~g}$. for 10 weeks.

10.1.49 Blood Wassermann reaction positive. Given a further course of neoarsphenamine $5 \cdot 25 \mathrm{~g}$. and bismuth $2.0 \mathrm{~g}$. for 10 weeks.

This is a very interesting case in the following respects :

(a) There was no possibility of his having infected his wife prior to treatment, and her infection must have occurred on his return from service overseas. On examination his blood showed a positive Wassermann reaction but no clinical signs of syphilis were detectable.

(b) He had early meningeal syphilis which was detected only by cerebrospinal-fluid examination, but which responded quickly to treatment.

(c) His blood tests are persistently positive in spite of considerable treatment.

(d) His wife suffers from latent syphilis also with persistently positive blood tests. Her cerebrospinal fluid has remained normal.

(e) Ante-natal treatment of his wife secured a healthy non-syphilitic child, which has been observed for two years.

Case 6 (46/5930).

April, 1946 Diagnosed as "early syphilis" but no record of blood tests given. Treated with $2 \cdot 4$ mega units penicillin.

June, 1946 Blood Wassermann reaction negative.

7.10.46 Tonsils enlarged and ulcerated. Uvula oedematous. Small ulcer near anal orificeexudate contained $T$. pallidum. Blood Wassermann reaction doubtful, Kahn test positive. No fresh exposure to infection admitted.

Re-treated with penicillin 10 mega units, neoarsphenamine, and bismuth. Further tests and cerebrospinal fluid consistently negative until 28.9.49, when he was discharged as cured.

This is a characteristic example of clinical and serological relapse 6 months after treatment with penicillin. Results since treatment, which included arsenical drugs and bismuth, have been satisfactory.

Case 7.(" $H$ ").

1946 Primary sero-positive syphilis. Treated with penicillin 2.4 mega units while in the Middle East. Had two blood tests and a lumbar puncture in the six months following treat- ment. Did not report for post-treatment observation on leaving the forces.

19.10.49 Routine examination, while serving a prison sentence, revealed no clinical evidence of syphilis. Blood Wassermann reaction positive.

26.10.49 Blood Wassermann reaction positive. Cerebrospinal fluid normal. Re-treated with 10 mega units penicillin, followed by neoarsphenamine $5.55 \mathrm{~g}$. and bismuth $2.0 \mathrm{~g}$. over 10 weeks.

28.12.49 Blood Wassermann remained positive. Treatment proceeding. Patient's wife, instructed to report to local clinic, was found to be suffering from latent syphilis which is being treated.

This is similar to Case 5. There is no possibility of his having infected his wife prior to treatment. He presumably suffered an infectious relapse, and marital infection occurred on his return from overseas.

\section{Discussion}

Observation for at least two years is essential before any claim' for cure of syphilis can be made. It is essential to try to assess the final results of treatment of syphilis with penicillin alone. There are many "ex-service" patients who, believing themselves cured, have not reported as instructed to civilian clinics for observation after release from the forces. Some of these men now have latent syphilis, and may develop late signs within the next decade, and some may have transmitted the disease to others (e.g. Cases 5 and 7). It is difficult in most cases to discriminate between relapse and re-infection. The eight cases recorded in detail illustrate this problem. It is considered safer to classify such patients as relapses, and treat them accordingly, unless the evidence in favour of reinfection is decisive.

The series reported is small and is not considered to be statistically significant, but similar small series occurring in clinics throughout the country could be considered as a whole.

A pooling of the findings could with advantage be used to elucidate not only this problem, but also other problems concerning venereal disease in Gt. Britain.

\section{REFERENCES}

Downing, C. C. R. (1950). British Journal of Venereal Diseases, 26, 31 .

Leifer, W. (1945). J. Amer. med. Ass., 129, 1247.

Pillsbury, D. M. (1945). British Journal of Venereal Diseases, 21, 139. 